ECCOMAS

Proceedia
COMPDYN 2021

$8^{\text {th }}$ ECCOMAS Thematic Conference on Computational Methods in Structural Dynamics and Earthquake Engineering M. Papadrakakis, M. Fragiadakis (eds.) Streamed from Athens, Greece, 28 - 30 June 2021

\title{
SEISMIC RESPONSE OF A TRANSPARENT PAVILION MADE OF STRUCTURAL GLASS
}

\author{
Dimitra V. Achillopoulou ${ }^{1,2}$, Nikoleta K. Stamataki ${ }^{3}$ \\ ${ }^{1}$ Civil Engineering Department, Democritus University of Thrace \\ University Campus, Xanthi \\ e-mail: dimiachi@civil.duth.gr \\ ${ }^{2}$ University of Surrey, Guildford, Surrey GU2 7XH, United Kingdom \\ d.achillopoulou@surrey.ac.uk \\ ${ }^{3}$ Civil Engineering Department, Democritus University of Thrace \\ University Campus, Xanthi \\ nikostam3@civil.duth.gr
}

\begin{abstract}
This paper deals with the design of a transparent pavilion (museum) made of structural glass. The fundamental concepts of structural glass are described and its application in public buildings. The work is focused on the seismic analysis of the glass structural members in regions with high seismicity. Particularly in these regions the basic principles of seismic isolation are taken into account and applied in the model building in order to avoid brittle failures. Analytical results show that the elastic behavior of structural glass doesn't affect the overall response of the building in seismic events if it is properly isolated. Especially, glass structural members with pseudo-ductile behavior have favorable effect on the seismic response and contribute towards accomplishing the codes' safety for public buildings.
\end{abstract}

Keywords: Structural Glass, Public Building, Seismic Design, Base Isolation 


\section{INTRODUCTION}

Glass has been one of the most well known structural materials since it was discovered back into the 1500 B.C. in Egypt and Mesopotamia and further developed in Rome during the $1^{\text {st }}$ century [1]. Lately in 1950, its use in structure become very popular by Alastair Pilkington who developed the process of the float glass production $(1,2)$. Due to its transparency and its high compressive and tensile strength, it was and remains the perfect material for the facades. As the years passed, the material affected the architectural rhythm and lately glass becomes the dominant material of the design [2]. Nowadays, after the progressive development of the material's properties and the new types of structural glass [1,2,3], the modern architecture trend to designing transparent buildings.

Apart from the esthetical value that the structural glass adds to the transparent buildings, it also shifts the negative impact on nature, since it is a full recyclable material [4]. The existing guidelines cover extensively the design of secondary structural elements $[5,6]$ and only lately there is an effort to develop codes for all the structural members. As such, buildings of this kind are rarely met, especially in Northern Europe and US [1], and the vast majority is museums or public buildings. However, there are a few if any examples of transparent buildings in high seismicity regions. For this reason, this paper deals with the investigation of the response of a transparent public building (pavilion) made of structural glass in regions with high probability of severe seismic events.

\section{STRUCTURAL GLASS}

\subsection{Mechanical properties}

The high strength and the glass resistance to acids and salt corrosion, makes glass suitable to be used as a structural material. Especially, due to the luck of porous it is not affected by the climatic conditions and the environmental exposure. This contributes to the durability of the material and hence the structural members.

Glass is an isotropic (density $\rho=2500 \mathrm{Kg} / \mathrm{m}^{3}$ ), elastic material with a modulus of elasticity approximately equal to $70 \mathrm{GPa}$, poison ratio ranging from 0.2 to 0.3 and a compressive strength more than $500 \mathrm{MPa}[6]$. The tensile strength depends on the chemical process of the production and varies from $45 \mathrm{MPa}$ to $120 \mathrm{MPa}[5,6]$.

It is worth noticing that, glass is considered a green material since it is fully recyclable and the energy need it for each production is considerably lower than that needed for compatible materials such as concrete and steel [7]. The use of glass needs special attention in order to provide energetically efficient buildings $[1,2,3]$.

\subsection{Types}

The glass when imposed on tensile loads, cracks initiate and propagate. With further chemical process new types of glass are developed with higher tensile strength and more resistant surface on the whole. Consequently, this shift of the tensile strength, leads to different failure modes and patterns. As such there are numerous types of glass e.g. annealed, full tempered, chemically and heat strengthened or composite forms such as laminated and reinforced glass. All these categories have brittle failure mode with large and sharp or round fragments after cracking whereas composite forms present a pseudo-plastic behavior with a combination of the above maintained failure modes. 


\section{DESIGN}

\subsection{Conceptual design of pavilion}

The glass pavilion of this study is orientated to be part of an internal part of an existing museum. The pavilion is considered as a unit which can be an interior or exterior extension and can form various configurations in any natural environment.

The pavilion is a one storey building $\left(\mathrm{H}_{\mathrm{lev}}=3.00 \mathrm{~m}\right)$ and has a total area equal to $53.00 \mathrm{~m}^{2}$ for hosting approximately 20 visitors. It consists of the exhibition room, the meeting room, reception, WC and traffic spaces as they are shown in the function diagram in Figure 1. The use of the spaces can differ according to the pavilion's demands and use. The basic conceptual design idea of the pavilion takes into consideration the proper ventilation and openings of the spaces, as well as the privacy and transparency. In case that there is a requirement for visual isolation, structural glass with controlled transparency can be used [1].

A main issue of the design with structural glass is the energy performance of the building $[1,2,3]$. Modern technology has lead to the development of various types of glasses e.g. reflective glass, insulting glass units, mirror glass and smart glasses $[1,8]$ that enhance the energy efficiency. It's worth mentioning that in the present work, the energy evaluation and the use of different energy glasses has not been examined and it is a task of future work.

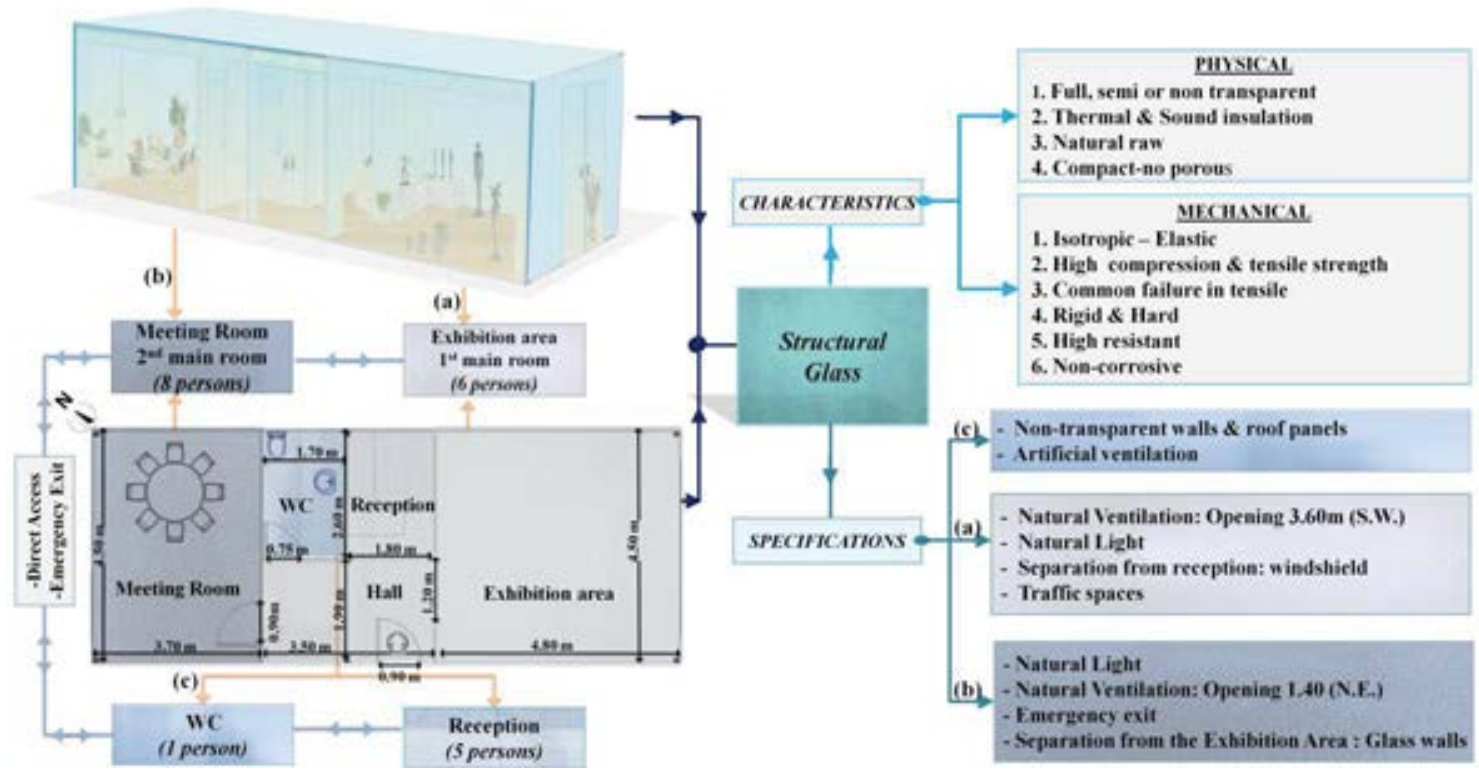

Figure 1: Function diagram of the glass pavilion

\subsection{Selection of structural members}

Structural glass is mainly a brittle material. Alternative types such as laminated or reinforced glass present a quasi pseudo-plastic behavior [9]. This response is favorable to the overall performance of buildings in high seismicity zones, offering the desirable safety level. As such, safety glass type is preferred to form the structural body of the current study. 
The glass moment frame consists of $\mathbf{H}$ shaped columns $\left(250 \times 250 \mathrm{~mm}^{2}\right)$ and rectangular beams $\left(66 \times 322 \mathrm{~mm}^{2}\right)$. The cross-section size is chosen so that the frame is resistant to gravity loads. Roof panels are designed to bear wind and snow loads. They are made of four sheets of full tempered laminated glass and they have total thickness equal to $40 \mathrm{~mm}$. The exterior glasses have $8.0 \mathrm{~mm}$ thickness each, in order to protect the middle glasses. The infill panels, which are designed to resist in wind load, are made from triplex laminated glass and each glass panel has $15 \mathrm{~mm}$ thickness. Columns are made of triplex laminated glass formed by three-layers of tempered glass of $22 \mathrm{~mm}$ thickness each, assembled with a transparent sentry glass interlayer (SG). This interlayer helps to keep together the fragments in case of failure in tension. Beams contain also a steel rebar $\left(22 \times 22 \mathrm{~mm}^{2}, \rho_{\mathrm{s}}=2.33 \%\right)$ mounted at the bottom part of the middle glass sheet which is heat-strengthened. The reinforcement is activated after the tensile failure of the cross section's glasses (heat-strengthened and tempered) and bears the tensile stresses developed without affecting significantly the transparency. Beams sheets are also kept together with a glass interlayer. The crack pattern of the fragments and the polymer defines the residual tensile strength of the member as it is shown in Figure 2. The steel reinforcement is also activated once the compressive loads exceed the compressive strength of the glass. Then fragments are created and kept in place by the SG interlayer.

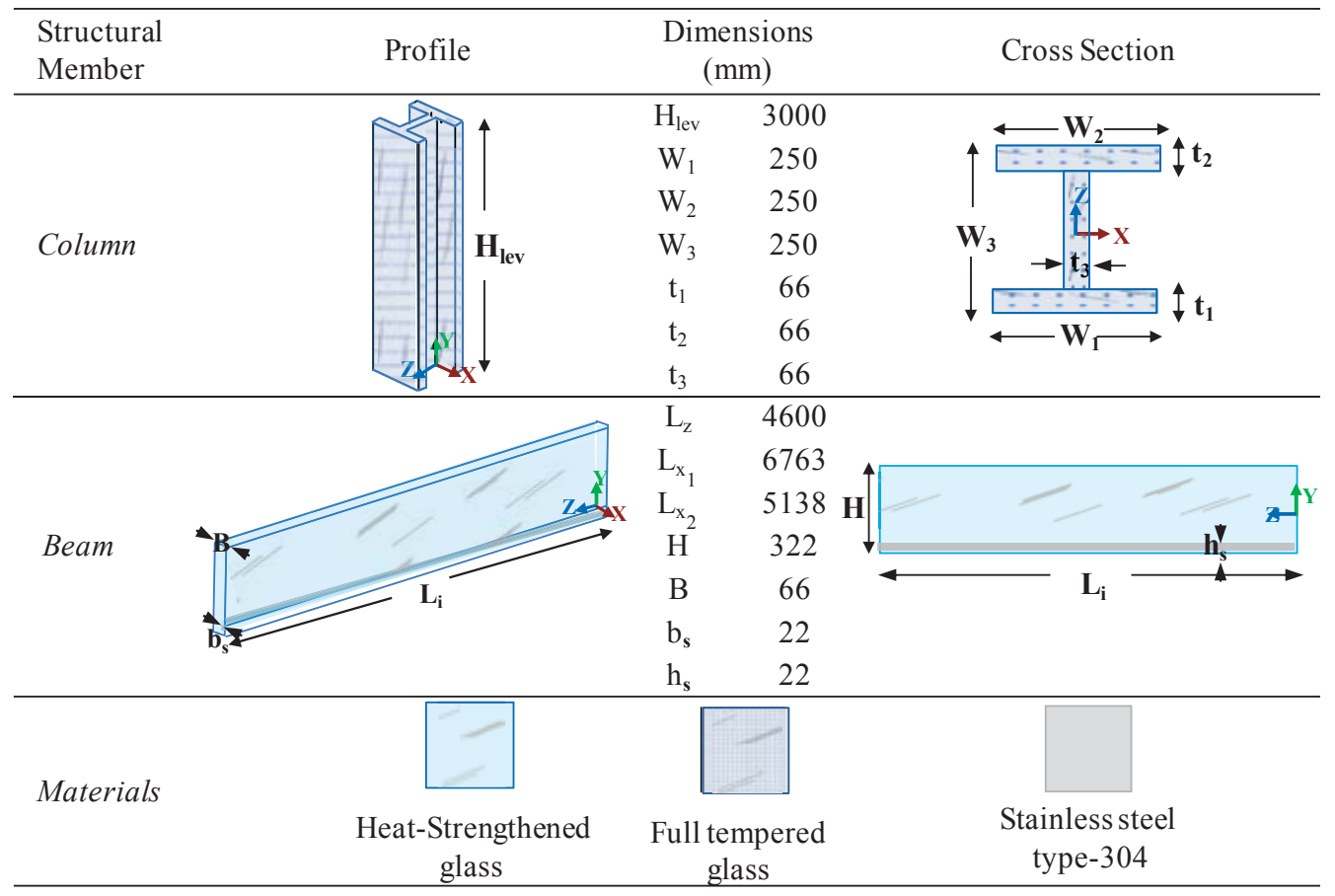

Table 1: Cross section's geometry

\subsection{Seismic design of the pavilion}

The pavilion's demands for seismic resistance are quantified with response spectra analysis (RSA) according to Eurocode (EC8/EN1998-1) [10] considering the seismic action as an elastic response spectrum. A preliminary modal analysis is performed in order to obtain the modal expansion (shapes).

The dynamic analysis is performed with the elastic response spectrum for the ground accelerations horizontal directions. The seismic action is represented by the elastic response spectrum, Type $1\left(\mathrm{M}_{\mathrm{s}}>5.5\right)$ and the elastic response of the structural glass denotes that the factor $\mathrm{q}$ is equal to 1.00 . 
According to EC8, the main factors that determine the elastic response spectrum are chosen. That is, soil conditions of type B, brittle type material and importance class of the building III. As such, the reference peak ground acceleration $\left(\mathrm{a}_{\mathrm{gR}}\right)$ for soil type B is equal to $0.36 \mathrm{~g}$ and the values of the characteristics periods $\left(\mathrm{T}_{\mathrm{B}}, \mathrm{T}_{\mathrm{C}}, \mathrm{T}_{\mathrm{D}}\right)$ and the soil factor $(\mathrm{S})$, are $0.15 \mathrm{sec}$, $0.50 \mathrm{sec}, 2.00 \mathrm{sec}$ and 1.20 respectively. The building seismic resistance is of importance in view of the consequences associated with a collapse (e.g. schools, museums etc) and thus is classified as importance class III with a corresponding importance factor $\left(\gamma_{\mathrm{I}}\right)$ equal to 1.20. Therefore the peak ground acceleration is equal to the reference peak ground acceleration $\left(\mathrm{a}_{\mathrm{g}}\right.$ $\left.=\gamma_{\mathrm{I}} \cdot \mathrm{a}_{\mathrm{gR}}\right) 0.43 \mathrm{~g}$ and the damping factor $(\eta)$ of the material is equal to $2 \%$, given the nature of the material [13].

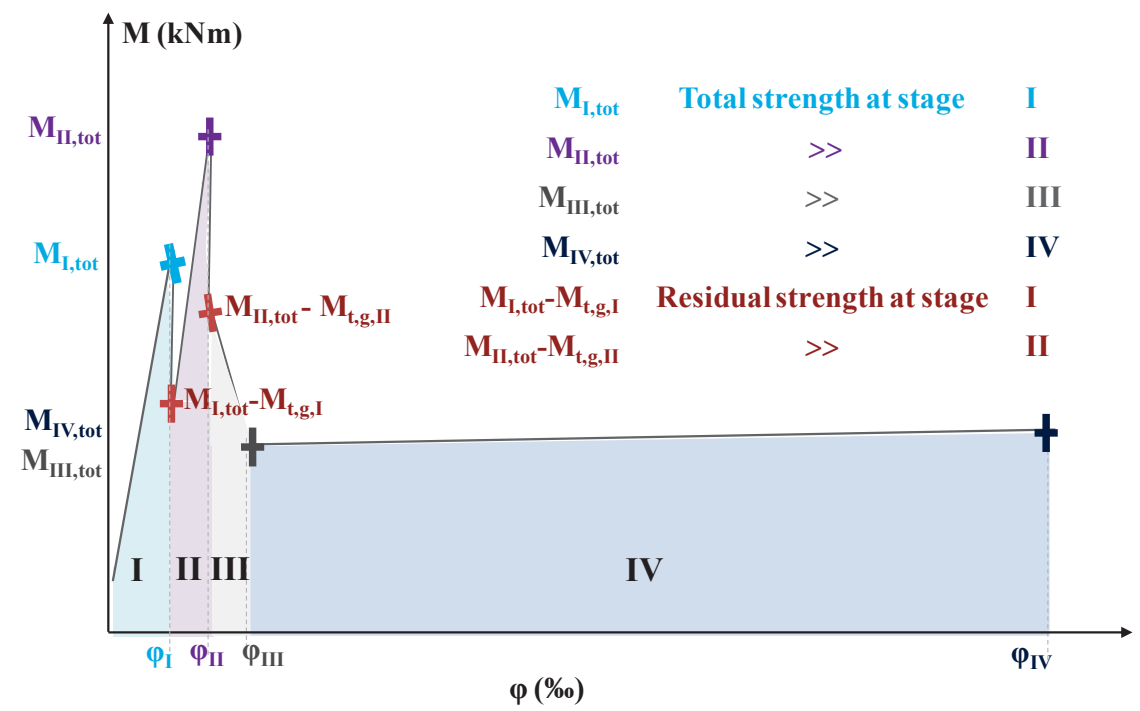

Non-Cracked: Stage I-Tensile failure of heat-strengthened glass; Cracked Stage: II-Tensile failure of full tempered glass and yield of steel; III-Intermediate yield point $\varepsilon_{y, s, I I}=2 \bullet \varepsilon_{, s, y} ; \mathbf{I V}$-Compressive failure of glass

Figure 2: M- $\varphi$ diagram

\subsection{Base isolation system}

Due to the high importance of the museum demands safety is increased. Especially in high seismicity zones according to EC8 the design should ensure that no collapse occurs. The glass pavilion's response of this study is mainly defined by the elastic nature and brittle failure of glass, which happens in small ranges of deformations. In order to limit them and to prevent failures from extreme earthquake events, the drift of the single degree of freedom (SDOF) pavilion should be reduced.

The glass pavilion is designed to be properly based in separate reinforced concrete foundations. In this paper a solution of base isolation system is chosen in order to decrease the maximum relative displacement of the foundation and the upper level of the structure $\left(\mathrm{H}_{\mathrm{lev}}\right)$. Various types of base isolation systems exist e.g. roller and ball bearings, sliding bearings, springs and elastomeric rubber bearings [11], with the most common in use the elastomeric rubber bearings (Low or High Damping Rubber Bearing LDRB/HDRB, Lead Rubber Bearing LRB and Friction Pendulous Systems FPS) [11]. The chosen base isolation system is one LDRB at the base of each column, made of natural rubber (NR) with a rectangular shape $\left(250 \times 350 \mathrm{~mm}^{2}\right)$ and a total height equal to $63 \mathrm{~mm}$. The bearing, is also reinforced with steel plates between the elastomer layers which provide high vertical stiffness $\left(\mathrm{K}_{\mathrm{v}}=418.90 \mathrm{kN} / \mathrm{mm}\right)$, 
considerably higher than the horizontal one $\left(\mathrm{K}_{\mathrm{h}}=1.50 \mathrm{kN} / \mathrm{mm}\right)$. This type of bearing is chosen since practically vertically it is restricted and incapable to deform. At the same time, it is flexible to withstand horizontal seismic displacements and rotations.

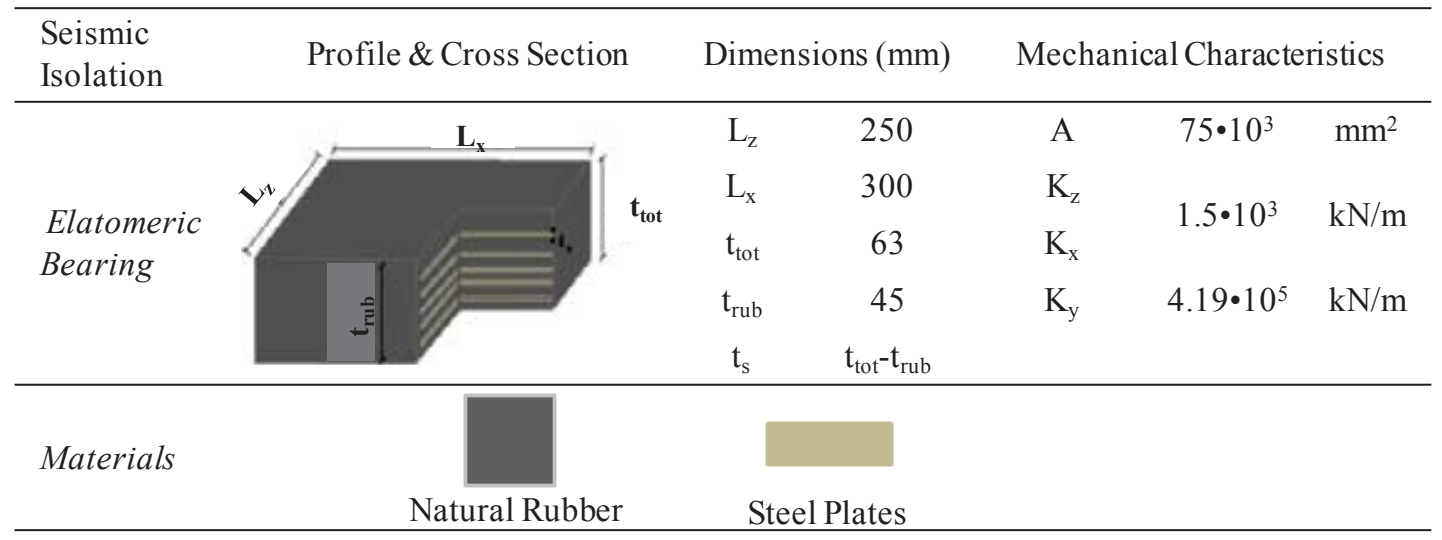

Table 2: Elastomeric rubber bearings' geometry

\section{SIMULATION}

The model building was numerical investigated using ANSYS software. The glass structural members (columns and beams) were simulated using a three-dimensional Finite Element Model (FEM). The roof of the building is considered as diaphragm, at the height of $3.0 \mathrm{~m}$. Proper finite element types were chosen for the simulation of glass columns (BEAM188), glass beams reinforced with steel rebars (REINF264) and the base isolation system (COMBIN14). Each bearing of the isolation system chosen is simulated with one spring for each direction with suitable stiffness, mechanical properties and stress strain laws, integrating the desired features of a certain base isolation system reducing the acceleration transmitted to the superstructure.

The two scenarios studied in this paper are a) a 3-D model of the glass pavilion without base isolation and b) a 3-D model of the glass pavilion based on elastomeric bearings (Figure $3)$.

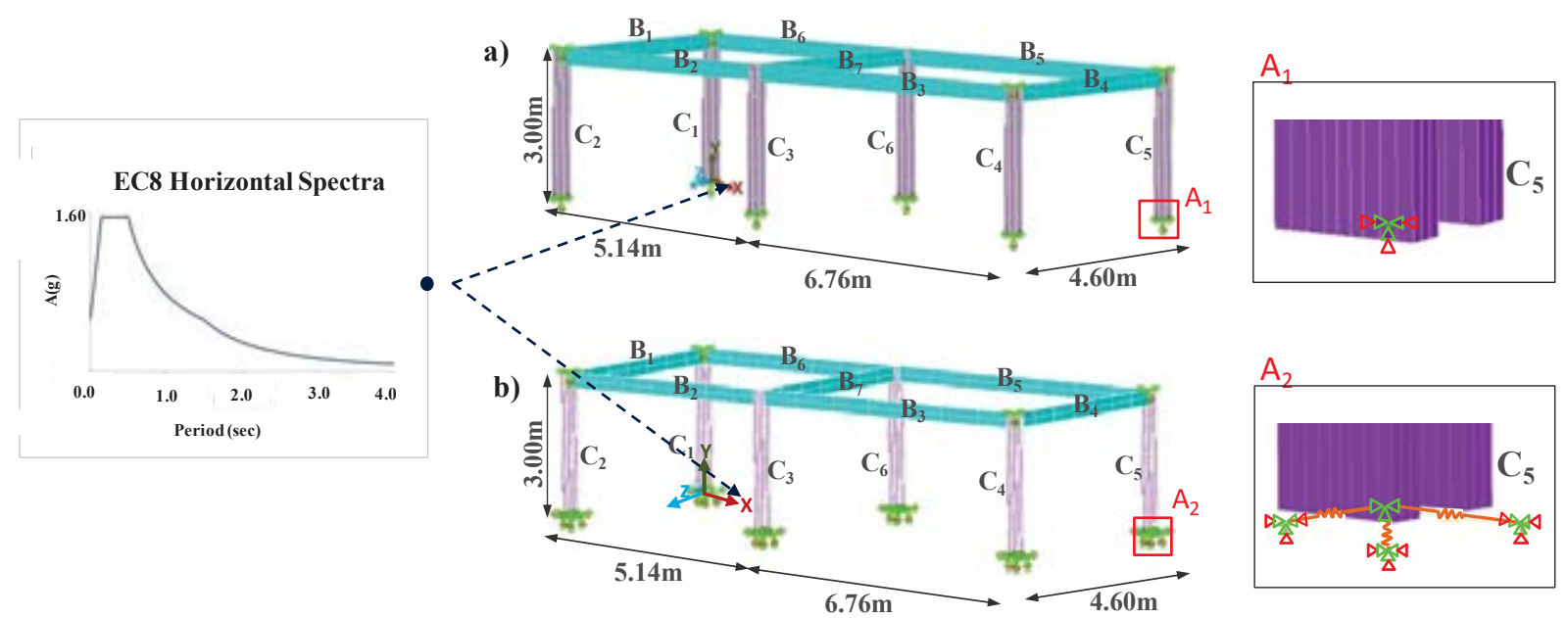

Figure 3: Two scenarios of study a) 3-D model without base isolation and b) 3-D model with base isolation 
The seismic design of the pavilion is performed according to the regulations of EC8. An elastic acceleration spectrum is applied representing the seismic load, which is excited in the horizontal plane (directions $\mathrm{x}$ and $\mathrm{z}$ ), neglecting the vertical seismic component (direction $\mathrm{y}$ ). The spectrum's excitation point coincides with the center of the global coordinate system, as shown in Figure 3. For the proper distribution of the pavilion's mass and the calculation of the mode shapes due to gravity, a modal analysis is performed followed by the spectrum analysis. After both the modal and spectrum analysis, the significant modes of the pavilion are combined. The solution in terms of displacement is extracted by using the square route of the sum of squares mode combination method (SRSS). [10,12]

The solution for both models a) without seismic base isolation system or b) isolated with elastomeric bearings, is extracted in terms of the relative displacement of the upper and lower nodes of the columns of each frame.

\section{RESULTS}

The response diagrams of the two different descried models are presented. First of the reference model which is represents the initial design's performance without base isolation system (circled shaped red dot line) and for the second model which represents the target design performance of the base isolated model (square shaped green dot line). The results are presented in terms of drift ratio of the storey (Figure 4a), maximum displacement vs. the amplitude of the natural frequency of the structure (Figure $4 \mathrm{~b}$ ) and of the maximum acceleration at the base vs. amplitude natural period (Figure 4c).

There is a significant reduction in structure's drift as it is illustrated in Figure 4a corresponding to $83 \%$ lower values in respect to the reference model. This reduction of drift expresses the capacity of the bearings to absorb the seismic displacements. Also, the significant decrease of the relative displacement in terms of absolute values is depicted in Figure $4 \mathrm{~b}$, where it is shown that the maximum relative displacement of the isolated model happens when the elastomeric bearing reaches its maximum shear capacity $(22.5 \mathrm{~mm})$, exhibiting also a larger cut off frequency. The cut off frequency of the initial design performance practically coincides with the natural frequency $\left(\mathrm{f}_{\mathrm{n}}\right)$ of the SDOF structure, which is reduced for the isolated model $(65 \%)$ and exhibiting a sharp increase at the ultimate design state of the elastomeric bearing. The Figure $4 \mathrm{c}$ shows the shift of the natural period and response with which the SDOF structure oscillates in the two different models at the ultimate state. Especially, the target design performance has a value of period 2.9 times greater than the initial. This elongation of the period is beneficial as the reference model oscillates with a maximum acceleration of $0.266 \mathrm{~g}$, whereas the base isolation decreases the maximum acceleration of the upper structure to $0.014 \mathrm{~g}$.

The base isolation system has an overall remarkable effect by favoring glass columns' deformation, eliminating brittle failures. Not only columns, but also beams do not have significant deformation as it shown in Figure 5 in terms of elastic strain. The value range of elastic strains of the isolated structure is between \pm 0.10 (Figure $5 \mathrm{~b}$ ), meaning $85 \%$ difference lower than the reference model (Figure 5a). These values of strains in all structural members corresponds to a curvature's value of stage I (Figure 2), which corresponds to non-cracked stage for all type of glasses both in tension and compression. 


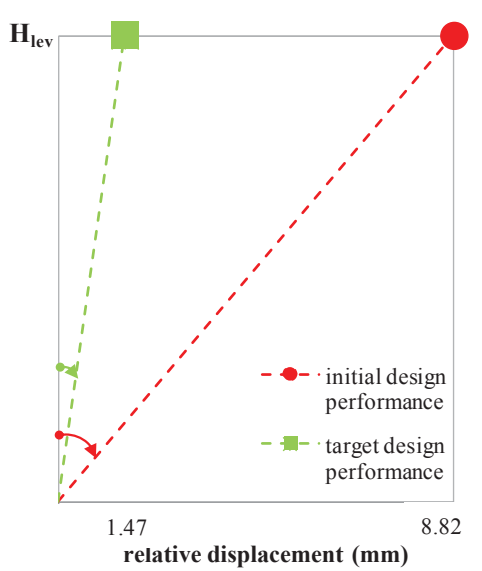

(a)

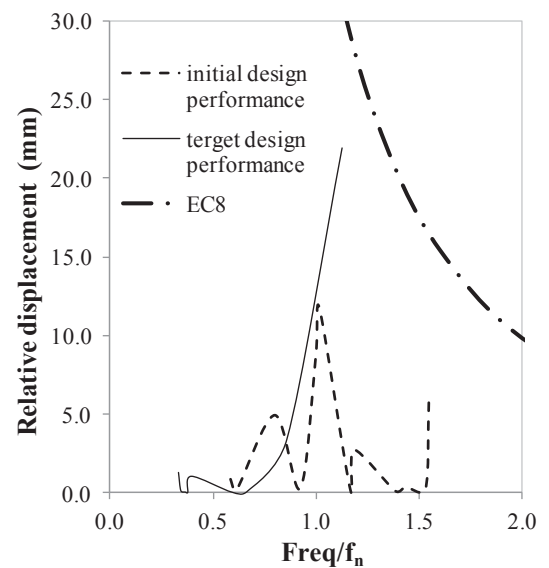

(b)

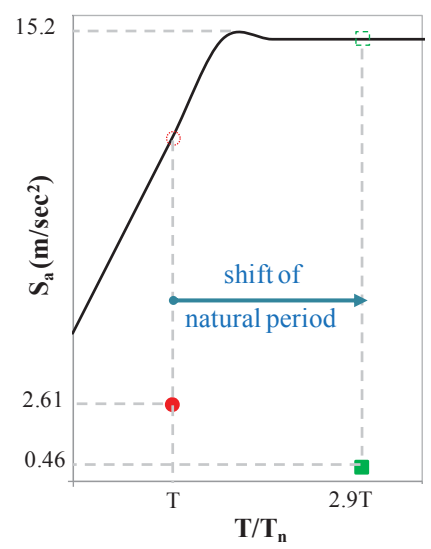

(c)

Figure 4: Results of the initial and target design performance in terms of: (a) Drift; (b) Relative displacementFreq/ $\mathrm{f}_{\mathrm{n}}$ and (c) $\mathrm{S}_{\mathrm{a}}(\mathrm{g})-\mathrm{T} / \mathrm{T}_{\mathrm{n}}$ diagrams

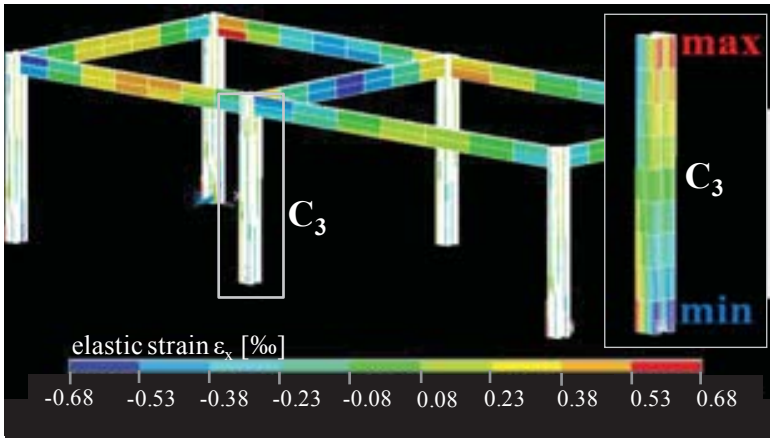

(a)

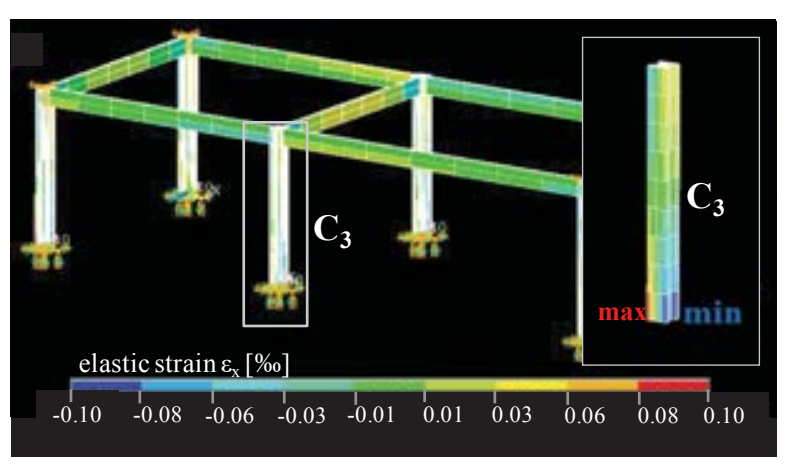

(b)

Figure 5: Elastic strain results for (a) non-isolated and (b) base isolated structure

\section{CONCLUSIONS}

- The isolated model exhibits a shift in the SDOF natural period and the significant reduction of the storey drift and the base acceleration, as well as the strains at the critical cross-sections of the structure. As such, glass exhibits no significant fracture or damage, even though is a brittle material. The proper design of the pavilion is proven to exhibit a high ratio of safety.

- A detailed selection of the structural glass type and in addition a proper layering of those types, in combination with structural steel, can lead in avoidance of brittle failures. Even though in the cases of columns the structural glass is proven to have enough resistance to deformations, the base isolation system enhances the overall performance.

- Further research is needed in order to study the connection assemblies between the structural members in order to assure that the abovementioned failure mode is achieved.

- The total displacement provoked from the seismic excitation can be dramatically reduced. Further investigation applying different isolation systems or a combination of them can result to the elimination of the displacement values, especially for different configurations of the unit model either vertically or horizontally. 


\section{REFERENCES}

[1] Garg, N. K. (Ed.). (2007), Guidelines for use of glass in Buildings, (P) Limited, Publishers. New Age International.

[2] Wurm, J. (2007), Glass structures: design and construction of self-supporting skins. Walter de Gruyter.

[3] Institution of Structural Engineers (Great Britain), (1999), Structural use of glass in buildings. London: Institution of Structural Engineers.

[4] DeBrincat, G., \& Babic, E. (2018). Re-Thinking the Life-Cycle of Architectural Glass, Glasgow: Arup.

[5] Buildings Department (2018), Code of Practice for Structural Use of Glass (the Code).

[6] Feldmann, M., Kasper, R., \& Abeln, B. (2014), Guidance for European structural design of glass components. Publications Office of the European Union, 1-196.

[7] Gutowski, T. G., Sahni, S., Allwood, J. M., Ashby, M. F., \& Worrell, E. (2013), The energy required to produce materials: constraints on energy-intensity improvements, parameters of demand. Philosophical Transactions of the Royal Society A: Mathematical, Physical and Engineering Sciences, 371(1986), 20120003.

[8] Gavrilović, D. J., \& Stojić, J. (2011). Usage of" smart" glass panels in commercial and residential buildings. Facta universitatis-series: Architecture and Civil Engineering, 9(2), 261-268.

[9] Louter, C., Belis, J., Veer, F., \& Lebet, J. P. (2012). Structural response of SGlaminated reinforced glass beams; experimental investigations on the effects of glass type, reinforcement percentage and beam size. Engineering Structures, 36, 292-301.

[10] Code, P. (2005). Eurocode 8: Design of structures for earthquake resistance-part 1: general rules, seismic actions and rules for buildings. Brussels: European Committee for Standardization.

[11] Warn, G. P., \& Ryan, K. L. (2012). A review of seismic isolation for buildings: historical development and research needs. Buildings, 2(3), 300-325.

[12] Morante, R., Wang, Y., Chokshi, N., Kenneally, R., \& Norris, W. (1999). Evaluation of modal combination methods for seismic response spectrum analysis.

[13] Lenk, P., \& Coult, G. (2016, June). Damping of glass structures and components. In Challenging Glass Conference Proceedings (Vol. 2, pp. 341-350). 